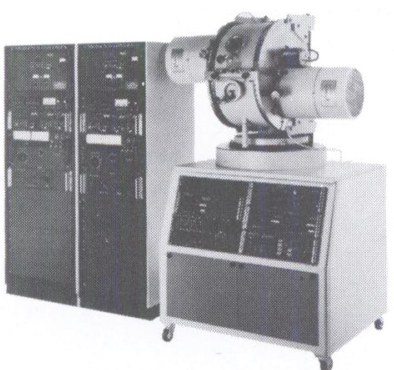

\title{
Veeco's Microetch ${ }^{\text {Tw }}$ technology both etches and deposits in a single process chamber.
}

Microetch ${ }^{\text {TM }}$ Dual Ion Source Systems etch and clean substrates and deposit precision thin film materials simultaneously or sequentially without exposing the substrate to atmosphere. In addition, processing is done at the lowest possible pressure.

Unlike conventional diode sputtering systems, Microetch ${ }^{\mathrm{T}}$ Systems let you maintain low substrate temperatures while controlling the angle of deposition. The result is the best combination of film adhesion without radiation damage.

Veeco designs and manufactures comprehensive systems, and offers extensive application and lab service support. To dis- cuss your application requirements, call or write: Veeco Instruments Inc., Terminal Drive, Plainview, NY 11803. 516-349-8300 or 800-833-2648.



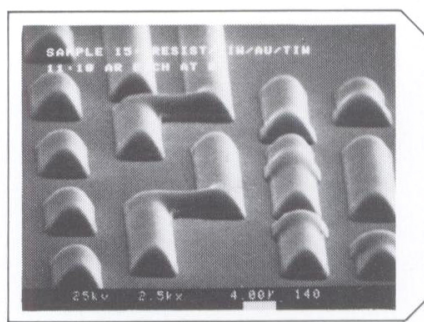

Gold metalization taper etch for GaAs high frequency devices using ion beam etching

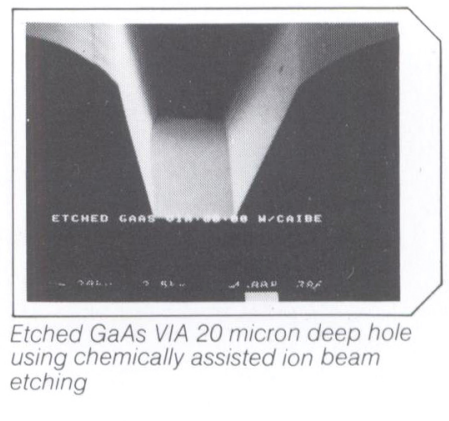

The collimated ion beam sputters a high purity target, precisely depositing the material on the substrate. As a result of the low arrival energies of deposited material, film density adhesion. alloy replication and film purity are excellent.
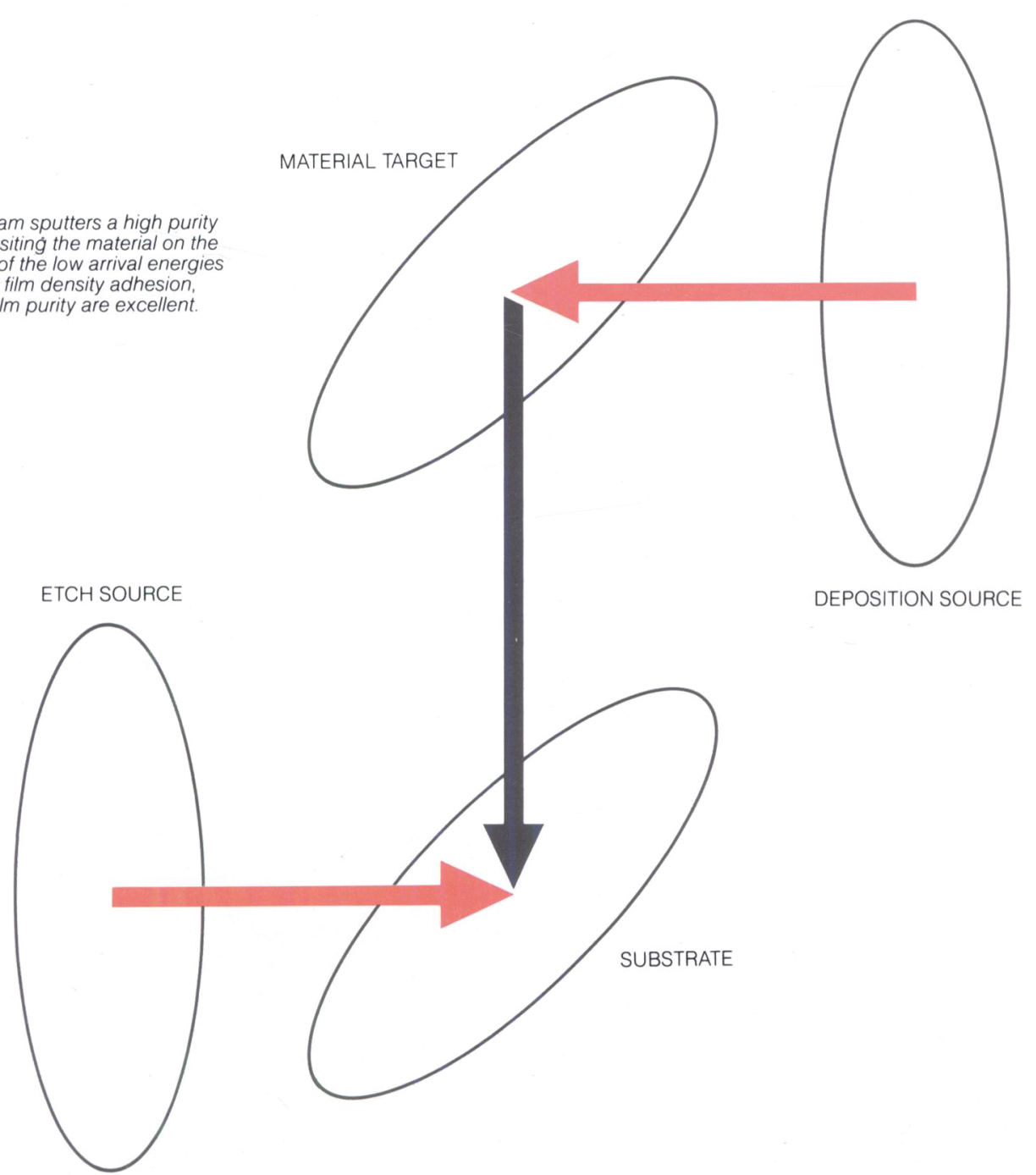

DEPOSITION SOURCE 


\section{SEE IT LIKE IT IS}

\section{TAKE THE "WAIT AND SEE" OUT OF YOUR X-RAY WORK.}



DIGITAL INTENSITY X-RAY IMAGE NHANCER system brings real time $x$-ray imaging to your lab. With a full $40 \mathrm{~mm}$ diameter input window and up to 200,000 gain. You can see immediately what film gives you later.

\section{CONTACT US FOR MORE INFORMATION:}

For inquiries on career opportunities with a leader in the electronic defense industry, contact us. We are an equal opportunity employer.

- acousto-optic ox-ray oinfrared systems

brimrose corporation of america 7720 belair rond



(301) $668-5800$

telex: $910-997-6817$ brimrosecorp fox: $301-668-5977$ 